\title{
Biomimetic three-dimensional nanocrystalline hydroxyapatite and magnetically synthesized single-walled carbon nanotube chitosan nanocomposite for bone regeneration
}

\author{
This article was published in the following Dove Press journal: \\ International Journal of Nanomedicine \\ 20 April 2012 \\ Number of times this article has been viewed
}

\author{
Owen $\mathrm{Im}^{1}$ \\ Jian $\mathrm{Li}^{2}$ \\ Mian Wang ${ }^{2}$ \\ Lijie Grace Zhang ${ }^{2,3}$ \\ Michael Keidar ${ }^{2,3}$ \\ 'Department of Biomedical \\ Engineering, Duke University, Durham, \\ NC; ${ }^{2}$ Department of Mechanical and \\ Aerospace Engineering, ${ }^{3}$ Institute for \\ Biomedical Engineering and Institute \\ for Nanotechnology, The George \\ Washington University, Washington, \\ DC, USA
}

Background: Many shortcomings exist in the traditional methods of treating bone defects, such as donor tissue shortages for autografts and disease transmission for allografts. The objective of this study was to design a novel three-dimensional nanostructured bone substitute based on magnetically synthesized single-walled carbon nanotubes (SWCNT), biomimetic hydrothermally treated nanocrystalline hydroxyapatite, and a biocompatible hydrogel (chitosan). Both nanocrystalline hydroxyapatite and SWCNT have a biomimetic nanostructure, excellent osteoconductivity, and high potential to improve the load-bearing capacity of hydrogels.

Methods: Specifically, three-dimensional porous chitosan scaffolds with different concentrations of nanocrystalline hydroxyapatite and SWCNT were created to support the growth of human osteoblasts (bone-forming cells) using a lyophilization procedure. Two types of SWCNT were synthesized in an arc discharge with a magnetic field (B-SWCNT) and without a magnetic field (N-SWCNT) for improving bone regeneration.

Results: Nanocomposites containing magnetically synthesized B-SWCNT had superior cytocompatibility properties when compared with nonmagnetically synthesized N-SWCNT. B-SWCNT have much smaller diameters and are twice as long as their nonmagnetically prepared counterparts, indicating that the dimensions of carbon nanotubes can have a substantial effect on osteoblast attachment.

Conclusion: This study demonstrated that a chitosan nanocomposite with both B-SWCNT and $20 \%$ nanocrystalline hydroxyapatite could achieve a higher osteoblast density when compared with the other experimental groups, thus making this nanocomposite promising for further exploration for bone regeneration.

Keywords: nanomaterials, single-walled carbon nanotube, nanocrystalline hydroxyapatite, chitosan, bone regeneration, biomimetic

\section{Introduction}

Although orthopedic implants, allografts, and autografts have been used to treat various orthopedic defects caused by trauma or disease, these traditional methods of treatment are complicated by the possibility of infection, improper healing from invasive surgeries, insufficient bone donations to seal gaps completely, and donor site morbidity. ${ }^{1,2}$ Developments in nanotechnology and tissue engineering have provided promising ways to repair and replace damaged bone. ${ }^{3,4}$ Human bone tissue is a nanocomposite with both organic and inorganic components. In particular, type I collagen and other proteins create a hydrated fibrous network that is mineralized
Correspondence: Lijie Grace Zhang Department of Mechanical and Aerospace Engineering and Institute for Biomedical Engineering, The George Washington University, 726 Phillips Hall, 80I 22nd Street NW,

Washington, DC 20052, USA

$\mathrm{Tel}+\mathrm{I} 2029942479$

$\mathrm{Fax}+\mathrm{I} 2029940238$

Email lgzhang@gwu.edu 
by nanocrystalline hydroxyapatite $\left[\mathrm{Ca}_{10}\left(\mathrm{PO}_{4}\right)_{6}(\mathrm{OH})_{2},\right]$ which is the main inorganic constituent in the bone extracellular matrix. The three-dimensional extracellular matrix plays a critical role in supporting and directing bone cell adhesion, proliferation, differentiation, and gene expression. Therefore, it is desirable to design a biomimetic three-dimensional nanostructured tissue-engineered scaffold that can mimic the natural extracellular bone matrix and provide an environment for new bone regeneration which is favorable to the cell.

Generally, an ideal tissue-engineered scaffold should satisfy several essential criteria. It should be: biocompatible with biomimetic nanosurface structure and chemistry to minimize the local tissue response while maximizing cell growth and tissue integration; porous to allow cell migration and efficient exchange of nutrients and wastes; biodegradable with a favorable degradation rate, allowing the scaffolds to provide structural support for initial cell growth and then gradually degrade after new tissue formation; and possess appropriate mechanical properties to support tissue growth under native mechanical loads. ${ }^{2,5-7}$

Due to their high water content, good permeability for oxygen, nutrients and other soluble signals, and the similarity of their characteristics to the fibrous bone extracellular matrix, various hydrogel scaffolds have been developed from, eg, chitosan, collagen, fibrin, hyaluronic acid, and alginate., These bioactive gels derive from natural sources, making them biocompatible for bone repair. For example, chitosan is produced by deacetylating chitin, which is a common biopolymer found in the exoskeletons of crustaceans and insects. Chitosan has been widely used in wound dressings and various tissue engineering applications, ${ }^{9-11}$ and has been shown to have good antibacterial properties. In addition, porous chitosan sponges have previously been demonstrated to be effective scaffolds for osteoblast proliferation. ${ }^{9,11}$ Chitosan is also biodegradable via lysosomes in the body. ${ }^{12}$ Therefore, biocompatible chitosan was used as the model matrix material in this study.

Although chitosan on its own is not very osteoconductive and also not very strong, the addition of hydroxyapatite as a secondary phase in hydrogels has been shown to increase osteoconductivity by providing sites for calcification. ${ }^{13}$ Hydroxyapatite is osteoconductive, nontoxic, noninflammatory, and promotes osteoblast proliferation. ${ }^{3}$ In addition, it has been reported that hydroxyapatite can increase the compressive strength of chitosan hydrogels. ${ }^{9}$ Furthermore, as one of the natural components in bone, nanocrystalline hydroxyapatite imitates the natural bone extracellular matrix, increasing surface area, wettability, and roughness, to optimize bone cell-specific protein interaction with cells when compared with micron size hydroxyapatite. ${ }^{14}$ Previous work has shown that nanocrystalline hydroxyapatite stimulates osteoblast proliferation more than microscale hydroxyapatite. ${ }^{15,16}$ In this study, biologically inspired nanocrystalline hydroxyapatite was synthesized via a hydrothermal treatment method. This treatment method can produce small grain sizes with high crystallinity of geometrically shaped biomimetic nanocrystalline hydroxyapatite rods at relatively low temperatures but under higher pressures.

Another important nanomaterial that was studied here is the single-walled carbon nanotube (SWCNT). SWCNT are rolled-up sheets of graphite cylinders with diameters typically around $1.4 \mathrm{~nm} .{ }^{17}$ Considering their excellent mechanical properties, cytocompatibility, and electrical properties, they have received a lot of attention for bone tissue engineering. ${ }^{18-23}$ Their nanofibrous geometry also simulates the extracellular matrix in bone. Carbon nanotubes can be synthesized through arc discharge, laser ablation, and chemical vapor deposition. Nanotubes formed using arc discharge have extremely high mechanical strength and flexibility, with elastic modulus values of $1 \mathrm{TPa} .{ }^{24}$ Therefore, in this study, an arc discharge method was adopted to synthesize SWCNT. More importantly, we applied a magnetic field during arc discharge synthesis in order to produce more biomimetic dimensions and fewer defects in the SWCNT. SWCNT were then incorporated as a third phase in our chitosan/nanocrystalline hydroxyapatite hydrogels to promote osteogenesis further.

In summary, a series of novel three-dimensional porous nanostructured chitosan/hydrothermally treated nanocrystalline hydroxyapatite/SWCNT hydrogel scaffolds were prepared using a freeze-drying procedure (lyophilization). After choosing an optimal ratio of biomimetic nanocrystalline hydroxyapatite to chitosan for osteoblast adhesion, two types of SWCNT, magnetically synthesized SWCNT (B-SWCNT) and nonmagnetically synthesized SWCNT (N-SWCNT), were investigated for the first time in chitosan composites for bone tissue engineering applications. Osteoblast responses towards these biomimetic nanostructured bone scaffolds were evaluated and discussed.

\section{Materials and methods \\ Nanomaterial synthesis}

Magnetically and nonmagnetically treated SWCNT

The N-SWCNT and B-SWCNT samples were both fabricated using an arc discharge method. The synthesis system consisted 
of a cylindrical reaction chamber made from stainless steel with a length of $254 \mathrm{~mm}$ and a diameter of $152 \mathrm{~m}$, and the cathode-anode assembly installed inside the chamber. The cathode was a solid graphite rod, and the anode was a hollow graphite rod. The mixture of graphite powder and a catalyst powder of nickel and yttrium was loaded into the anode, keeping the total molar radio of $\mathrm{C}: \mathrm{Ni}: \mathrm{Y}$ at 94.8:4.2:1. After pumping down the chamber to vacuum, helium gas was filled and the pressure was kept around 500 Torr by an Omega CN-8502 controller during the synthesis process. All experiments were done with a fixed arc current of about $75 \mathrm{~A}$ and a discharge voltage of $30 \mathrm{~V}$. In regard to the sample of B-SWCNT, an additional permanent magnet was placed inside the chamber at a $25 \mathrm{~mm}$ distance from the central axis of the electrodes to provide a 0.06 Tesla magnetic field in the gap between electrodes.

\section{Nanocrystalline hydroxyapatite}

Hydroxyapatite was precipitated using a wet chemistry method, ${ }^{25}$ as illustrated in the following equation. First, ammonium phosphate (0.6 M, Sigma-Aldrich, St, Louis, MO) was added to Millipore distilled and deionized water and stirred. Ammonium hydroxide (Fisher Scientific, Waltham, MA) was used to adjust the $\mathrm{pH}$ of the solution to 10 . Then calcium nitrate (1 M, Sigma-Aldrich) was added dropwise (approximately $3.6 \mathrm{~mL} /$ minute), and the amorphous hydroxyapatite was allowed to precipitate out for 10 minutes without stirring:

$$
\begin{aligned}
& 6\left(\mathrm{NH}_{4}\right)_{2} \mathrm{HPO}_{4}+10 \mathrm{Ca}\left(\mathrm{NO}_{3}\right)_{2}+8 \mathrm{NH}_{4} \mathrm{OH} \\
& \quad=\mathrm{Ca}_{10}\left(\mathrm{PO}_{4}\right)_{6}(\mathrm{OH})_{2}+20 \mathrm{NH}_{4} \mathrm{NO}_{3}+6 \mathrm{H}_{2} \mathrm{O}
\end{aligned}
$$

Furthermore, one quarter of the supernatant was removed after centrifugation. The remaining precipitate and aqueous solution were then transferred to a $125 \mathrm{~mL}$ Teflon liner, which was sealed in a Parr Acid Digestion Bomb (Parr Instrument, Moline, IL). Nanocrystalline hydroxyapatite was prepared by hydrothermally treating amorphous hydroxyapatite in the Parr system at $200^{\circ} \mathrm{C}$ for 20 hours. The final particles were rinsed with distilled and deionized water three times, dried overnight at $80^{\circ} \mathrm{C}$, and ground with a mortar and pestle to obtain fine particles.

\section{Biomimetic three-dimensional porous nanostructured scaffold fabrication} Chitosan/nanocrystalline hydroxyapatite scaffolds

Unmodified chitosan scaffolds (controls) were prepared by adding chitosan (Sigma-Aldrich) to $2 \%$ acetic acid and stirring for one hour to dissolve the chitosan fully. The solution was homogenized by sonicating for 10 minutes, then distributed in a cylindrical mold and frozen at $-80^{\circ} \mathrm{C}$ for several hours. The samples were lyophilized in a Labconco freeze-dry system overnight to create interconnected porous structures. ${ }^{26,27}$

Scaffolds with nanocrystalline hydroxyapatite concentrations of 5,10 , and $20 \mathrm{wt} \%$ were prepared. For a $5 \%$ nanocrystalline hydroxyapatite in chitosan nanocomposite, $0.475 \mathrm{~g}$ chitosan was added to $2 \%$ acetic acid and stirred for one hour. Meanwhile, $0.025 \mathrm{~g}$ nanocrystalline hydroxyapatite was combined with $2 \%$ acetic acid and sonicated for 8 minutes to distribute the particles homogeneously. This nanocrystalline hydroxyapatite mixture was added dropwise to the chitosan solution under stirring. As before, the solution was homogenized by 10 minutes of sonication, distributed in molds, frozen at $-80^{\circ} \mathrm{C}$, and lyophilized. Pictures of the resulting three-dimensional porous scaffolds are shown in Figure 1.

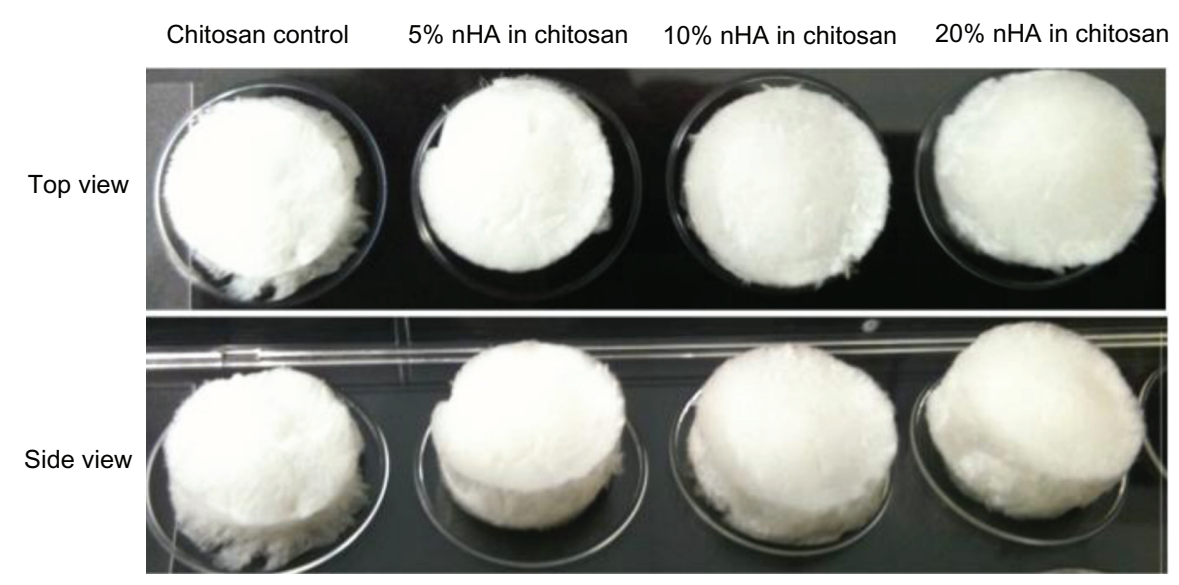

Figure I Fabricated chitosan/nHA scaffolds after freeze-drying.

Note: Dimensions of scaffolds were $\mathrm{I} \mathrm{cm}$ in diameter and $2 \mathrm{~mm}$ in thickness. 
The freeze-dried nanoscaffolds were rinsed with $1 \mathrm{M}$ $\mathrm{NaOH}$ to neutralize the acid. Scaffolds were sterilized by soaking in $70 \%$ ethanol and drying at $60^{\circ} \mathrm{C}$. Finally, the scaffolds were further sterilized under ultraviolet light for 30 minutes and then rinsed twice with phosphate-buffered saline before cell seeding.

\section{Chitosan/nanocrystalline hydroxyapatite/ SWCNT scaffold}

The $1 \mathrm{wt} \% \mathrm{~N}-\mathrm{SWCNT}$ and B-SWCNT were incorporated into the chitosan scaffold. Briefly, two types of SWCNT were separately sonicated in $2 \%$ acetic acid and added to stirring chitosan solutions to prepare chitosan scaffolds with N-SWCNT or B-SWCNT. A chitosan nanocomposite scaffold incorporating both $20 \mathrm{wt} \%$ nanocrystalline hydroxyapatite and B-SWCNT/N-SWCNT was fabricated as well. After sonicating SWCNT in the acetic acid, 20\% nanocrystalline hydroxyapatite was added to the mixture and sonicated to disperse the nanoparticles. The homogenous mixture was then put into a chitosan solution, as before. All of the samples were poured into cylindrical molds, lyophilized, neutralized with $\mathrm{NaOH}$, and sterilized, as described earlier.

\section{Characterization of SWCNT, nanocrystalline hydroxyapatite, chitosan nanocomposites}

\section{Electron microscopy imaging}

B-SWCNT, N-SWCNT, and nanocrystalline hydroxyapatite morphologies were characterized by transmission electron microscopy. The N-SWCNT and B-SWCNT samples were each sonicated for 60 minutes (Fisher Scientific 150T dismembrator) in preparation for morphology observation by transmission electron microscopy (JEOL 1200 EX, Tokyo, Japan). Nanocrystalline hydroxyapatite was also sonicated before coating onto carbon-coated copper grids (EM Sciences, Hatfield, PA) and characterized at a $100 \mathrm{kV}$ acceleration voltage.

A scanning electron microscope operating at a $2 \mathrm{kV}$ accelerating voltage was used to characterize the well dispersed nanocrystalline hydroxyapatite/B-SWCNT in chitosan hydrogels. The lyophilized nanocomposite substrates were sputter-coated with a thin layer of gold palladium. Scanning electron microscopic images of the nanocomposites were taken under a Zeiss Ultra-60 field emission scanning electron microscope.

\section{Hydrogel swelling and water content}

The swelling behavior and equilibrium water content of different concentrations of nanocrystalline hydroxyapatite
$(0 \%, 5 \%, 10 \%$, and $20 \%)$ embedded in the chitosan hydrogels were measured. The dry weight $\left(W_{d r y}\right)$ of various chitosan scaffolds was measured after drying for 3 hours at $60^{\circ} \mathrm{C}$, and the fully swollen hydrogel weight $\left(W_{\text {wet }}\right)$ was taken after submerging the scaffolds in phosphate-buffered saline until equilibrium and removing excessive surface water with filter paper. The swelling ratio and equilibrium water content could be calculated from the following equations:

$$
\begin{aligned}
& \text { Swelling ratio }(\%)=\frac{\left(W_{w e t}-W_{d r y}\right)}{W_{d r y}} \times 100 \\
& \text { Water content }(\%)=\frac{\left(W_{w e t}-W_{d r y}\right)}{W_{w e t}} \times 100
\end{aligned}
$$

\section{Water contact angle and surface energy}

Measurements of the water contact angle were recorded using a water contact angle analyzer (DSA1, Krüss, Germany) to determine the hydrophilicity of the various nanocrystalline hydroxyapatite chitosan hydrogels, as previously described by Zhang et al. ${ }^{28}$ Before measurement, a $0.5 \mathrm{~mm}$ thick layer of nanocrystalline hydroxyapatite/ chitosan was cast on glass in order to obtain a relatively flat hydrogel surface. Static contact angles were measured 10 seconds after placing $3 \mu \mathrm{L}$ of distilled and deionized water on the sample surfaces. Surface energy $\left(\mathrm{E}_{\text {surface }}\right)$ was calculated using the equation $\mathrm{E}_{\text {surface }}=\mathrm{E}_{\mathrm{lv}} \times \cos \theta$, where $\mathrm{E}_{\mathrm{lv}}=72.8 \mathrm{~mJ} / \mathrm{m}^{2}$ at $20^{\circ} \mathrm{C}$ for pure water and $\theta$ is the measured contact angle. ${ }^{29}$ All experiments were conducted in ambient conditions and were performed at least five times per sample.

\section{Mechanical testing of nanocrystalline hydroxyapatite} and SWCNT nanocomposites

The tensile and compressive mechanical properties of $20 \%$ nanocrystalline hydroxyapatite in chitosan, $20 \%$ nanocrystalline hydroxyapatite + B-SWCNT in chitosan and chitosan controls were determined using a universal testing machine (ATS 900, Applied Test Systems, Butler, PA) at room temperature. The initial cross-sectional area and thickness of each sample were measured before testing. The extension and compression rates were $2 \mathrm{~mm} /$ minute and $5 \mathrm{~mm} /$ minute. Load and displacement data were recorded by the computer software provided by Applied Test Systems and converted to stress-strain curves via Excel. The Young's moduli were calculated from the slope of the initial linear region of the respective stress-strain curves. At least four samples were evaluated for each composition. 


\section{Osteoblast responses to three-dimensional biomimetic nanostructured bone scaffolds}

Osteoblast adhesion in chitosan/nanocrystalline hydroxyapatite scaffolds

Human fetal osteoblasts (CRL-11372, American Tissue Culture Collection, Manassas, VA) were cultured in Dulbecco's Modified Eagle's Medium (Invitrogen, Grand Island, NY) supplemented with $10 \%$ fetal bovine serum (Hyclone, Logan, UT) and 1\% penicillin/streptomycin (Hyclone) under standard cell culture conditions of $37^{\circ} \mathrm{C}$, and a $5 \% \mathrm{CO}_{2} / 95 \%$ humidified air environment. Cells with population numbers of $6-10$ were used in the experiments without further characterization.

Chitosan scaffolds with $0 \%, 5 \%, 10 \%$, and $20 \%$ concentrations of nanocrystalline hydroxyapatite were tested in the first cell adhesion study. All of the sterilized scaffolds were preincubated in Dulbecco's Modified Eagle's Medium for 30 minutes and osteoblast cells were seeded at 3500 cells $/ \mathrm{cm}^{2}$. The seeded scaffolds were then incubated under standard cell culture conditions for 4 hours. After rinsing the substrates twice with phosphate-buffered saline, the adherent cells were fixed by immersing the scaffolds in $10 \%$ formaldehyde (Fisher Scientific) for 10 minutes, and then washing subsequently with phosphate-buffered saline. Cell nuclei were stained with DAPI (Invitrogen). Cell counts were taken for five different fields of view per sample under a fluorescence microscope (Olympus BX60). Experiments were run in triplicate and repeated at least three times for each sample. Through this adhesion study, the optimized nanocrystalline hydroxyapatite concentration in chitosan hydrogel for the best cytocompatibility was determined.

\section{Osteoblast adhesion/proliferation in chitosan/ nanocrystalline hydroxyapatite/SWCNT scaffolds} In the next cell adhesion study, the B-SWCNT/N-SWCNT nanocomposites were included in the experimental groups. All of the experimental groups are shown in Figure 2. Osteoblast cells were seeded using the same procedure as in the first set of cell studies. After 4 hours of incubation, a live/dead viability/ cytotoxicity kit (Molecular Probes, Grand Island, NY) was used to determine cell viability on the scaffolds of interest in the present study. Cells adherent on each scaffold were stained with a mixture of calcein $\mathrm{AM} 2 \mu \mathrm{M}$ and ethidium homodimer- $14 \mu \mathrm{M}$ according to the manufacturer's instructions and incubated at $37^{\circ} \mathrm{C}$ for 30 minutes. Dead and live cells were counted at approximately $490 \mathrm{~nm} / 530 \mathrm{~nm}$ wavelengths (excitation/ emission) for calcein AM and $560 \mathrm{~nm} / 640 \mathrm{~nm}$ wavelengths for ethidium homodimer-1, respectively, under a fluorescence microscope for five fields of view per sample. There were three rounds of cell tests, again with three samples per round.

For a proliferation study, osteoblasts were seeded ( $2500 \mathrm{cell} / \mathrm{cm}^{2}$ ) onto the $20 \%$ nanocrystalline hydroxyapatite in chitosan, $20 \%$ nanocrystalline hydroxyapatite + B-SWCNT in chitosan, and chitosan controls, and were then cultured for 1, 3, and 7 days. At each time point, the attached cells were fixed, stained, and counted under a fluorescence microscope, similar to the procedure described earlier.

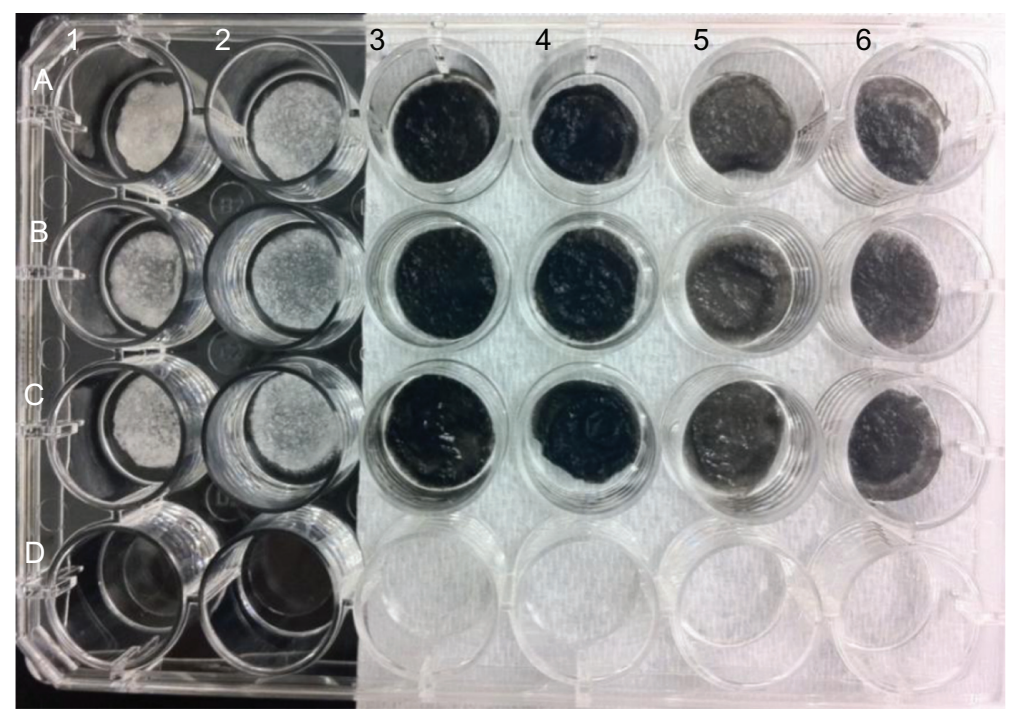

Figure 2 Pictures of chitosan/nHA/SWCNT samples.

Notes: AI-Cl: chitosan scaffolds; A2-C2: 20\% nHA in chitosan; A3-C3: N-SWCNT in chitosan; A4-C4: N-SWCNT + 20\% nHA in chitosan; A5-C5: B-SWCNT in chitosan; A6-C6: B-SWCNT + 20\% $\mathrm{nHA}$ in chitosan; and DI-D3: glass references. 


\section{Osteoblast spreading morphology}

In order to image the osteoblast spreading morphology for the different three-dimensional chitosan nanocomposites, osteoblasts were seeded at a density of $3500 \mathrm{cells} / \mathrm{cm}^{2}$ on the scaffolds of interest and were cultured under standard cell culture conditions for 24 hours. They were fixed using $10 \%$ formaldehyde for 10 minutes and $0.1 \%$ Triton X-100 (Sigma-Aldrich) for 5 minutes. Osteoblasts were then doubly stained with DAPI and rhodamine-phalloidin (staining F-actin filaments, Molecular Probes) to examine cell spreading. Cell morphologies were imaged under a Zeiss LSM 710 confocal microscope.

\section{Statistical analysis}

A one-way analysis of variance, followed by a Turkey's post hoc test, was used to determine possible significant differences between groups and evaluate the statistical significance of the data, which was considered at $P<0.05$.

\section{Results and discussion \\ Characterization of nanocrystalline hydroxyapatite, B-SWCNT, and N-SWCNT}

Figure 3A and B compare the morphology of N-SWCNT without a magnetic field and B-SWCNT synthesized with a nonuniform magnetic field. It can be seen that the B-SWCNT sample is close-packed into bundles due to Van der Waals interactions between the individual B-SWCNT, with bundle diameters ranging from 2 to $20 \mathrm{~nm}$. In contrast, the N-SWCNT sample had larger diameters of bundles and individual nanotubes, which is consistent with the analysis based on our previous Raman spectrum. ${ }^{30}$ In addition to carbon nanotubes, in the sample of B-SWCNT, few-layer graphene can be found, which increased the conductivity of the sample, as shown in Figure 3C. The hexagonal dot pattern of electron diffraction (inset of Figure 3C) shows evidence of well-ordered graphene crystal structures. Previous investigations have also demonstrated that the magnetically enhanced arc discharge can narrow the diameter distribution of metallic catalyst particles and carbon nanotubes, increase the length of SWCNT, as well as change the ratio of metallic and semiconducting carbon nanotubes. ${ }^{31,32}$

The hydrothermally treated nanocrystalline hydroxyapatite particles were rod-like in shape, as shown in Figure 4A and $\mathrm{B}$. Their average dimensions were about 50-100 nm in length and $20-30 \mathrm{~nm}$ in width, similar to natural bone minerals. The images also show clusters of nanocrystalline hydroxyapatite particles. This corresponds to measurements reported from our previous studies, ${ }^{25}$ which demonstrated that hydroxyapatite nanoparticles can easily conglomerate into particles with dimensions on a micron scale. During the fabrication of the scaffolds, nanocrystalline hydroxyapatite solution was ultrasonicated for at least 8 minutes to ensure an even distribution of nanocrystalline hydroxyapatite throughout the scaffolds. In addition, the nanocrystalline hydroxyapatite prepared by hydrothermal treatment also had desirable crystallinity (data not shown here).

\section{Characterization of nanostructured scaffolds}

\section{Morphology and mechanical properties}

The lyophilized chitosan hydrogel scaffolds were threedimensional, porous, and foamy structures, as shown in Figure 1. Specifically, all of the nanocrystalline

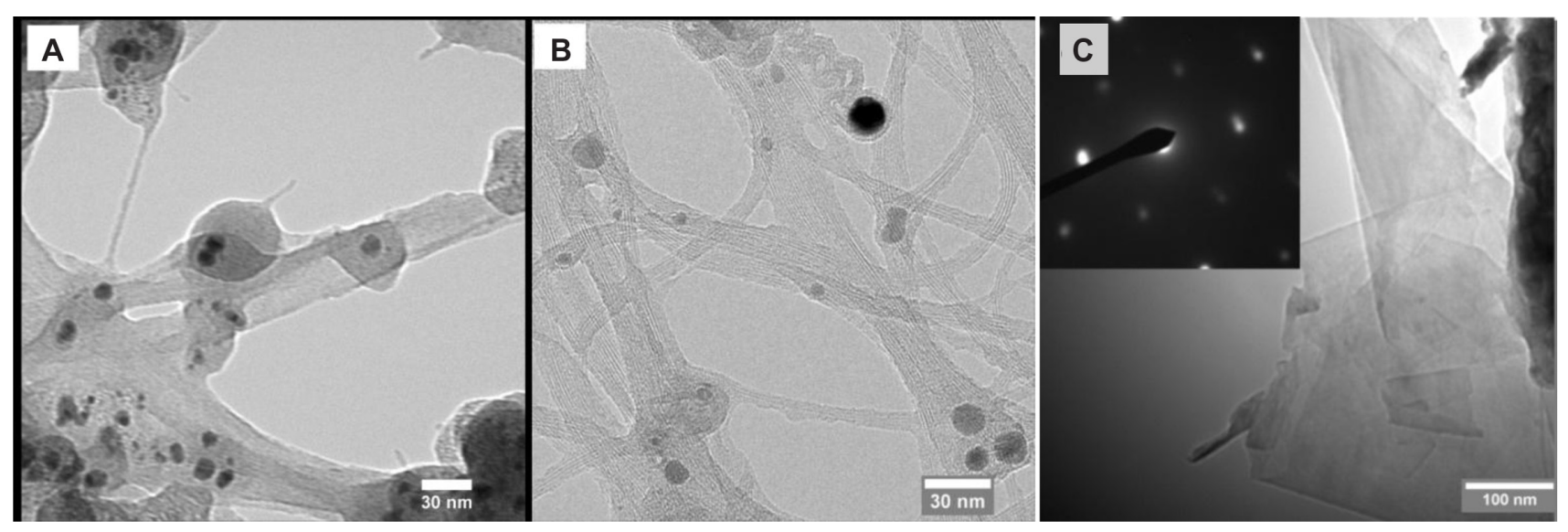

Figure 3 TEM images of (A) single-walled carbon nanotubes without magnetic field (N-SWCNT); (B) single-walled carbon nanotubes with magnetic field of 0.06 Tesla (B-SWCNT); and (C) graphene flakes with magnetic field of 0.06 (B-SWCNT). Inset of figure (C) is the selected area electron diffraction pattern showing the crystalline structure of graphene. 

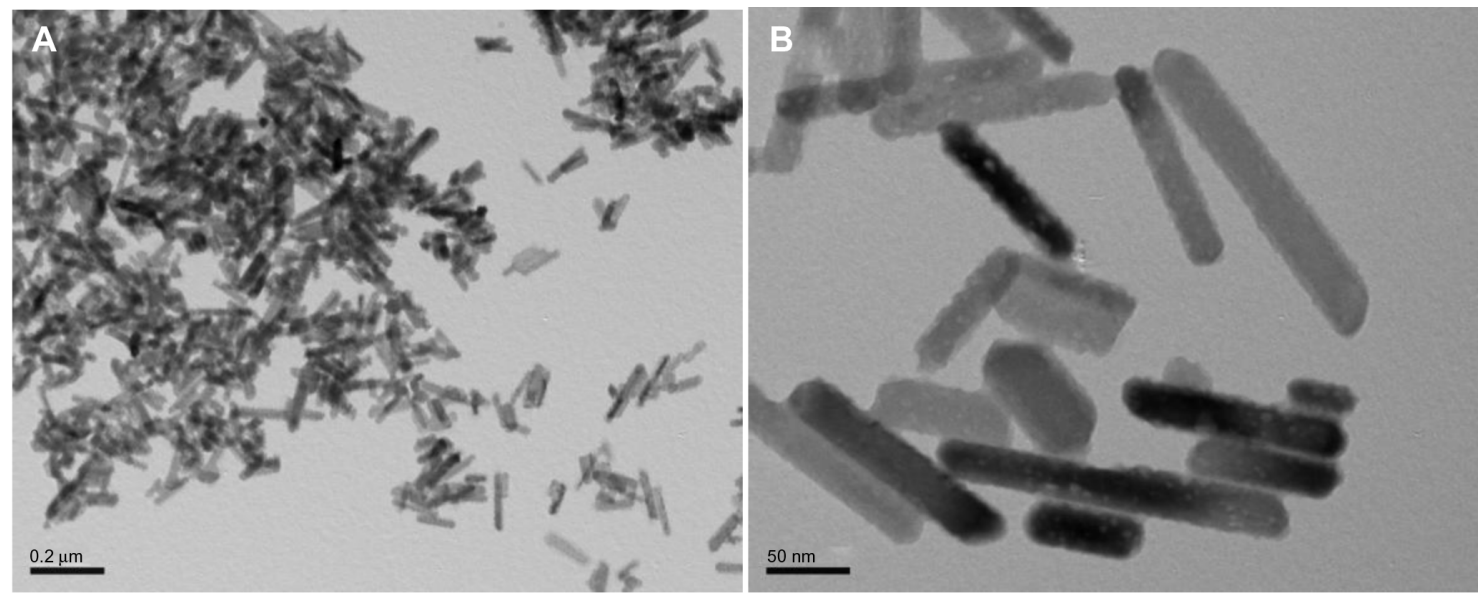

Figure 4 TEM images of biomimetic nanocrystalline hydroxyapatite with (A) low and (B) high magnifications.

hydroxyapatite/chitosan scaffolds were white, but when they were soaked in phosphate-buffered saline, differences in opacity became apparent. Scaffolds with higher nanocrystalline hydroxyapatite content were more opaque, as a result of nanocrystalline hydroxyapatite particle additions and related microstructure to nanostructure changes. The addition of SWCNT turned the entire scaffold a black color. B-SWCNT chitosan scaffolds were a little lighter in color when compared with N-SWCNT chitosan scaffolds, as shown in Figure 2.

Scanning electron micrographs (Figure 5) show a typical chitosan/nanocrystalline hydroxyapatite/SWCNT scaffold with rich porous micron-sized structures inside. These interconnected pores can contribute to the retention of a large amount of water in the chitosan. Because of the macroporous structure of the chitosan hydrogels shown by scanning electron microscopy, cellular infiltration into this scaffold is anticipated. Furthermore, these pores can easily allow water and other nutrients in, while allowing removal of waste from embedded cells.

Moreover, the tensile and compressive test results show (Figure 6) that both nanocrystalline hydroxyapatite particles and SWCNT could improve the Young's modulus of the scaffolds. In particular, $20 \%$ nanocrystalline hydroxyapatite and SWCNT in chitosan can significantly enhance the tensile and compressive moduli when compared with the chitosan controls. It has been shown that SWCNT and nanocrystalline hydroxyapatite particles can improve the mechanical properties of various scaffolds. ${ }^{15,20,33}$ Through the incorporation of SWCNT and nanocrystalline hydroxyapatite particles in the soft hydrogel system, we can reinforce the chitosan scaffold.

\section{Swelling properties, surface hydrophilicity, and surface energy of scaffolds}

Figure 7 reveals that the swelling ratios of all of the chitosan/ nanocrystalline hydroxyapatite hydrogels exceeded $600 \%$,
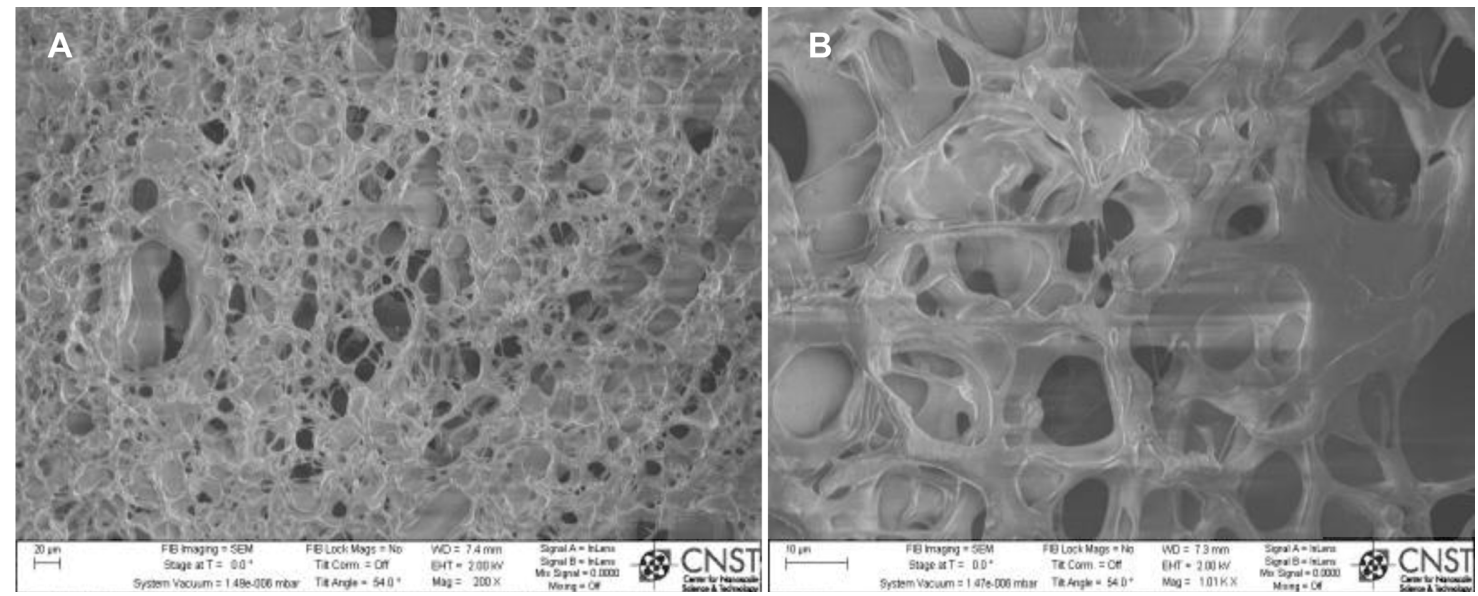

Figure 5 SEM images of 3D porous chitosan with nHA and magnetically synthesized B-SWCNTs: (A) low and (B) high magnifications. 

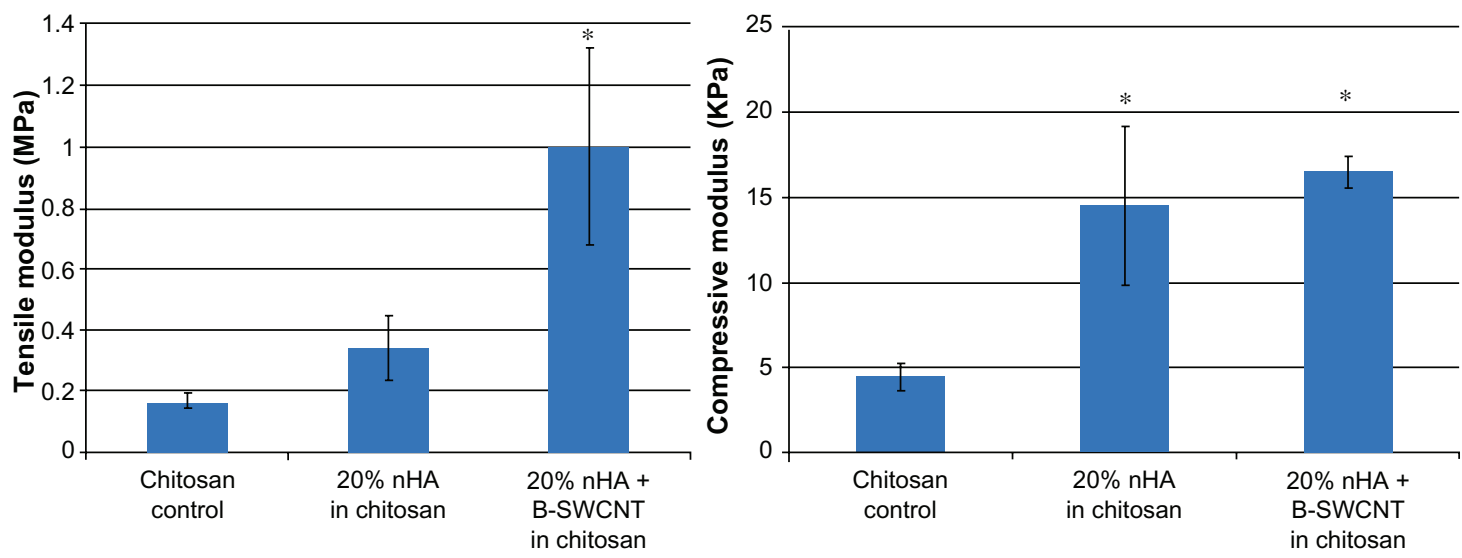

Figure 6 Tensile and compressive modulus of three chitosan scaffolds. $20 \%$ nHA + B-SWCNTs in chitosan has the highest modulus. Note: Data are mean \pm SEM; $n=4$. $* P<0.05$ when compared to chitosan controls.

and the equilibrium water content of all the samples was extremely high $(>86 \%)$. Swelling and water content were inversely proportional to the nanocrystalline hydroxyapatite content in these scaffolds: ie, $20 \%$ nanocrystalline hydroxyapatite in chitosan had a much lower swelling ratio (643.6\%) and water absorption (86.5\%) than those of chitosan controls (938.7\% and $90.4 \%$, respectively). Because there is less elastic chitosan in scaffolds with higher ratios of stiff nanocrystalline hydroxyapatite, this result is expected.

Surface wettability and surface energy of biomaterials are believed to be related to cell adhesion, proliferation, and differentiation on the substrate. ${ }^{34,35}$ In our study, the water contact angles of chitosan/nanocrystalline hydroxyapatite were all $<80^{\circ}$, indicating the hydrophilic behavior of these scaffolds and suitability for osteoblast attachment. However, chitosan did not vary significantly in contact angle measurements because hydrophilicity only decreased slightly after the incorporation of nanocrystalline hydroxyapatite (Table 1). Further, there were no significant differences in surface energy between the nanocrystalline hydroxyapatite chitosan scaffolds.

\section{Osteoblast responses}

\section{in the nanostructured scaffolds}

Osteoblast adhesion in chitosan/nanocrystalline hydroxyapatite scaffolds

The 4-hour cell adhesion study showed that nanocrystalline hydroxyapatite plays an important role in improving the cytocompatibility properties of the chitosan scaffold (Figure 8).

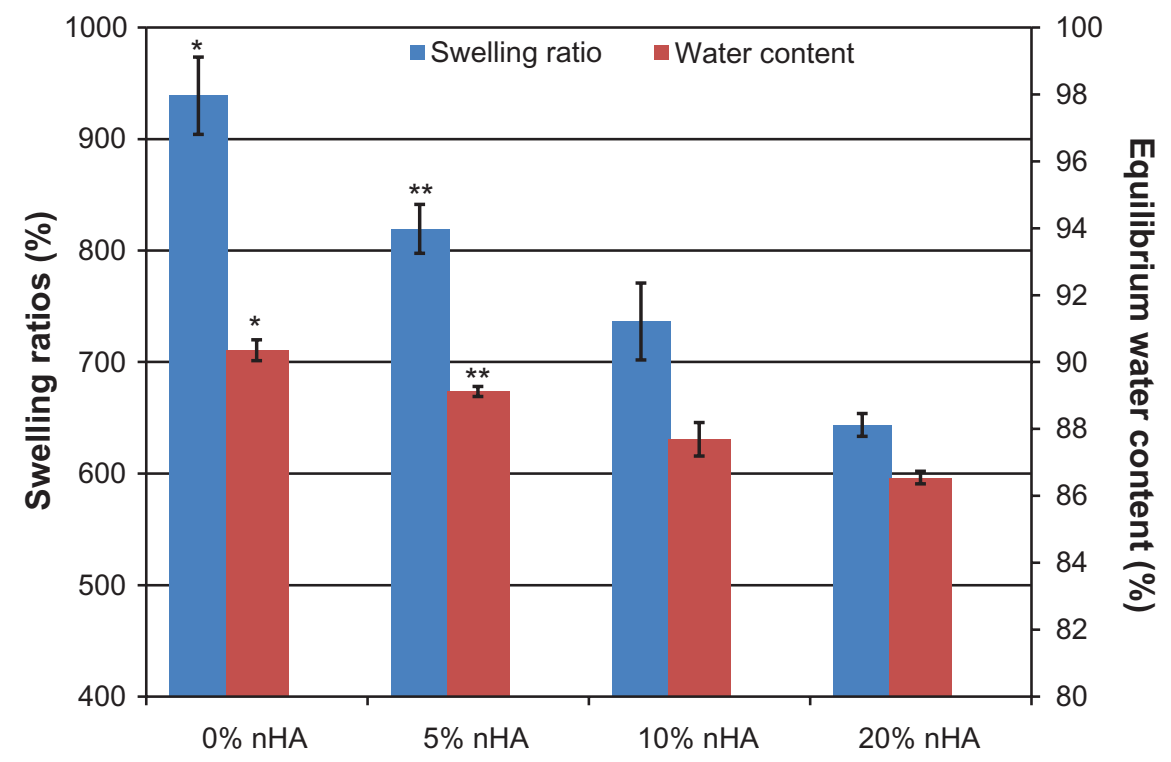

Figure 7 Swelling ratios and equilibrium water contents in various chitosan/nHA hydrogel scaffolds. Swelling and water content were inversely proportional to nHA content in scaffolds.

Notes: Data are mean \pm SEM; $\mathrm{n}=3 . * \mathrm{P}<0.05$ when compared to all of other chitosan scaffolds; $* * P<0.05$ when compared to $10 \%$ and $20 \% \mathrm{nHA}$ chitosan scaffolds. 
Table I Surface wettability and surface energy after adding different $\mathrm{nHA}$ concentration into chitosan hydrogels

\begin{tabular}{lll}
\hline nHA content & $\begin{array}{l}\text { Contact angle theta } \\
\text { (degree) }\end{array}$ & $\begin{array}{l}\text { Surface energy } \\
\left(\mathrm{mJ} / \mathbf{m}^{2}\right)\end{array}$ \\
\hline $0 \%$ & $76.70 \pm 5.81$ & $16.75 \pm 7.15$ \\
$5 \%$ & $75.67 \pm 2.52$ & $18.01 \pm 3.08$ \\
$10 \%$ & $76.26 \pm 2.73$ & $17.29 \pm 3.36$ \\
$20 \%$ & $75.02 \pm 1.30$ & $18.81 \pm 1.38$ \\
\hline
\end{tabular}

Note: Data are mean \pm standard deviation, $n=5$.

A positive trend of increasing osteoblast adhesion and increasing nanocrystalline hydroxyapatite concentrations in the chitosan scaffolds was observed. Specifically, $20 \%$ nanocrystalline hydroxyapatite in a chitosan scaffold could achieve the highest density of adherent cells when compared with the other samples. Osteoblast adhesion on the $20 \%$ nanocrystalline hydroxyapatite scaffolds was $59 \%$ greater than on the pure chitosan controls. Our result indicate that increasing the nanocrystalline hydroxyapatite concentration increased the cytocompatibility of the scaffolds. Given that approximately $70 \%$ of human bone matrix is composed of nanohydroxyapatite, ${ }^{36}$ nanocrystalline hydroxyapatite in scaffolds could contribute to designing a scaffold with biomimetic chemical components encouraging greater osteoblast adhesion. In addition, considering the increase in opacity as well as elastic modulus and the decrease in swelling ratios with the increase of nanocrystalline hydroxyapatite concentration in chitosan, a higher ratio of nanocrystalline hydroxyapatite could also contribute to microstructural changes in the scaffolds and create a biologically inspired nanostructured scaffold for better bone cell attachment. Based on this first round of cell adhesion studies, the $20 \mathrm{wt} \%$ nanocrystalline hydroxyapatite concentration was chosen for further investigation.

\section{Osteoblast adhesion/proliferation in chitosan/ nanocrystalline hydroxyapatite/MWCNT scaffolds}

In this study, we not only fabricated a nanostructured chitosan scaffold by incorporating hydrothermally treated biomimetic nanocrystalline hydroxyapatite, but also designed a novel scaffold with both nanocrystalline hydroxyapatite and magnetically/nonmagnetically synthesized SWCNT. The result of the present study demonstrate for the first time that when combining biologically inspired nanocrystalline hydroxyapatite chitosan hydrogels with both types of SWCNT, osteoblast adhesion can be greatly augmented (Figure 9). In particular, osteoblast adhesion in $20 \%$ nanocrystalline hydroxyapatite + B-SWCNT in chitosan was highest when compared with the other experimental groups. $20 \%$ nanocrystalline hydroxyapatite + N-SWCNT in chitosan also promoted osteoblast attachment when compared with N-SWCNT and $0 \%$ nanocrystalline hydroxyapatite in chitosan. These results suggest that the addition of SWCNT to a nanocrystalline hydroxyapatite chitosan scaffold may have a synergistic effect of improving their cytocompatibility properties, thereby making them promising for bone regeneration. Essentially, all of the scaffolds incorporating SWCNT or nanocrystalline hydroxyapatite showed enhanced osteoblast adhesion compared

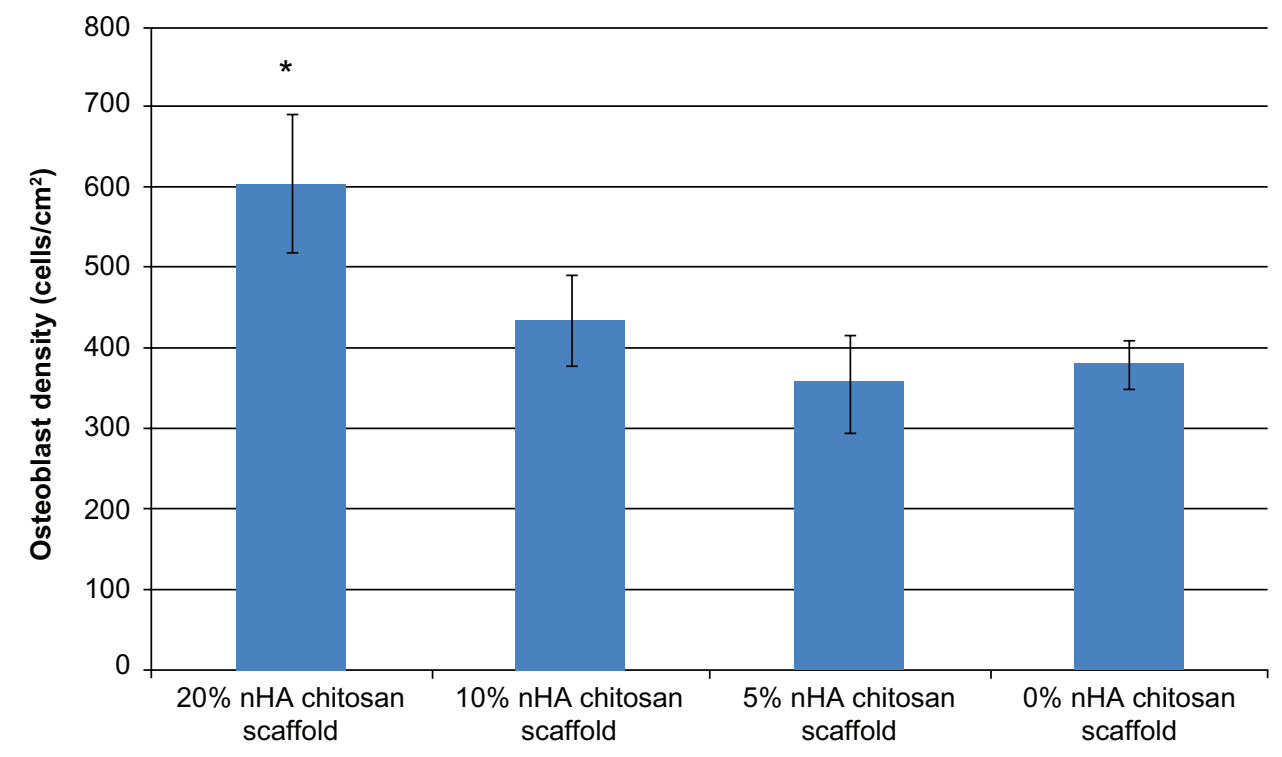

Figure 8 Human fetal osteoblast adhesion in different concentrations of hydrothermal treated chitosan/nHA scaffold. $20 \% \mathrm{nHA}$ in chitosan scaffold can get highest osteoblast attachment.

Note: Data are mean $\pm \mathrm{SEM} ; \mathrm{n}=9 . * \mathrm{P}<0.05$ when compared to $0 \%$ and $5 \% \mathrm{nHA}$ chitosan scaffolds. 


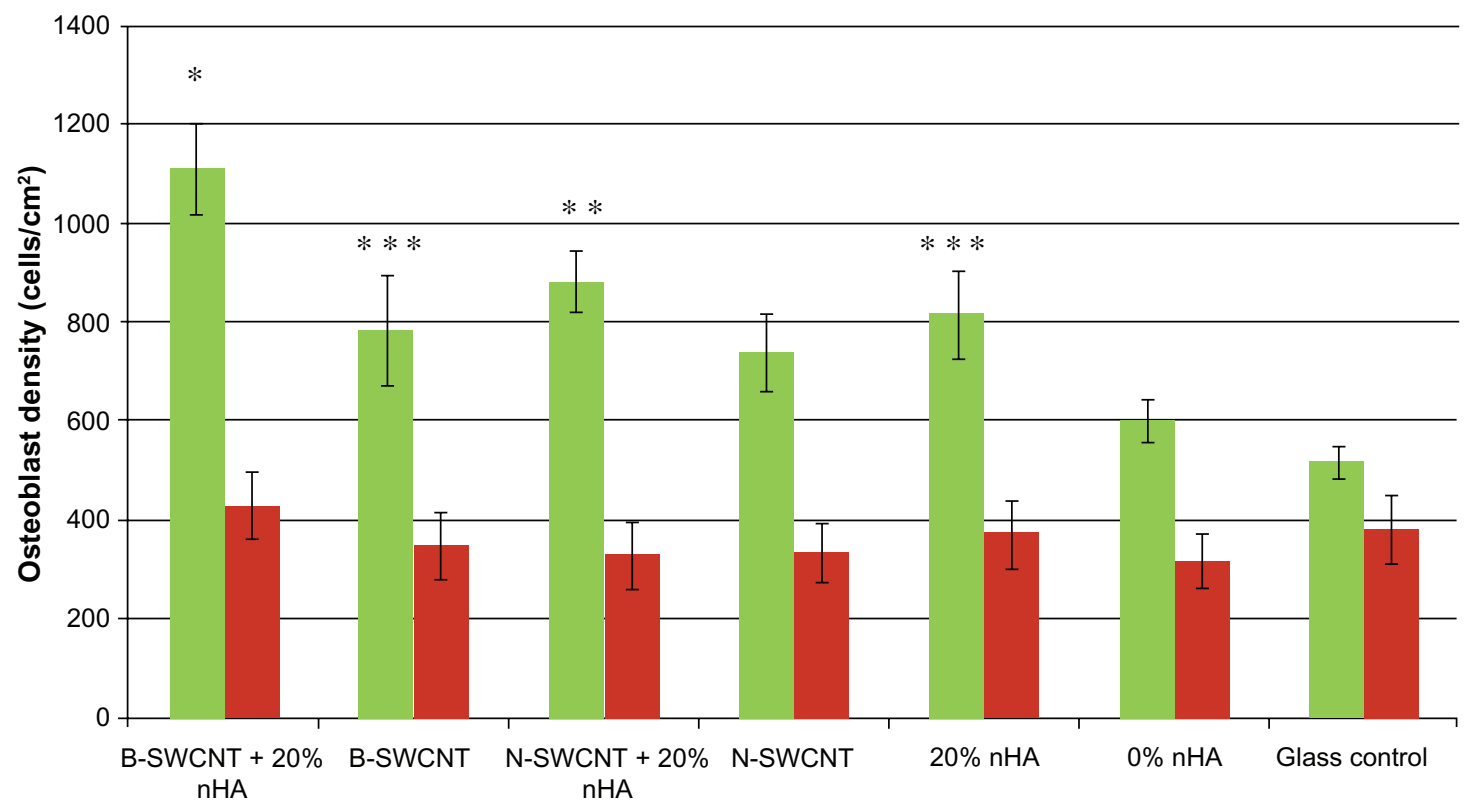

Figure 9 Greatly enhanced osteoblast adhesion in nanostructured chitosan with nHA and magnetically treated B-SWCNTs.

Notes: Data are mean \pm SEM; $\mathrm{n}=9$. $* \mathrm{P}<0.05$ when compared to all other experimental groups; $* * \mathrm{P}<0.05$ when compared to $\mathrm{N}$-SWCNT (untreated), $0 \% \mathrm{nHA}$ in chitosan, and glass references; and $* * * P<0.05$ when compared to $0 \% \mathrm{nHA}$ in chitosan. Green bar and red bar represent live cells' number and dead cells' number, respectively.

with chitosan controls without nanocrystalline hydroxyapatite and SWCNT. These results can be explained by considering how the surface properties and interior structure of chitosan scaffolds were changed by embedding them with different nanomaterials. The nanostructured nanocrystalline hydroxyapatite and SWCNT contribute to changes in the chitosan surface to amplify nanoroughness and improve the surface area of the whole scaffold. Webster et al have reported that nanophase ceramics and nanotube composites may improve osteoblast function by increasing protein (including vitronectin and fibronectin) adsorption on nanophase materials with increasing surface nanoroughness. ${ }^{14,34,37}$ Obviously, the biomimetic nanometric sizes of nanocrystalline hydroxyapatite and SWCNT play a critical role in improving osteoblast adhesion
Live cells
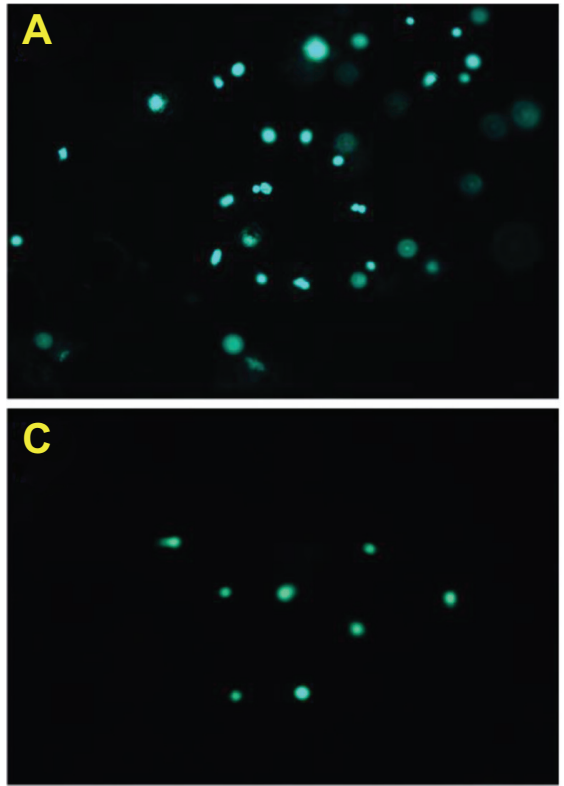

Dead cells
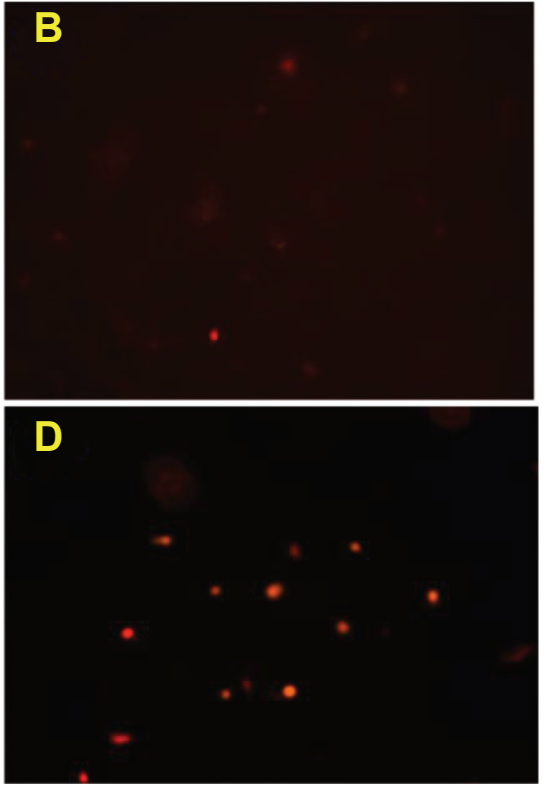

Figure 10 Fluorescent microscopy images of $20 \% \mathrm{nHA}+\mathrm{B}-\mathrm{SWCNT}$ chitosan scaffold stained by calcein A and ethidium homodimer B for (A) live and (B) dead cells; Glass references stained for $(\mathbf{C})$ live and $(\mathbf{D})$ dead cells. 


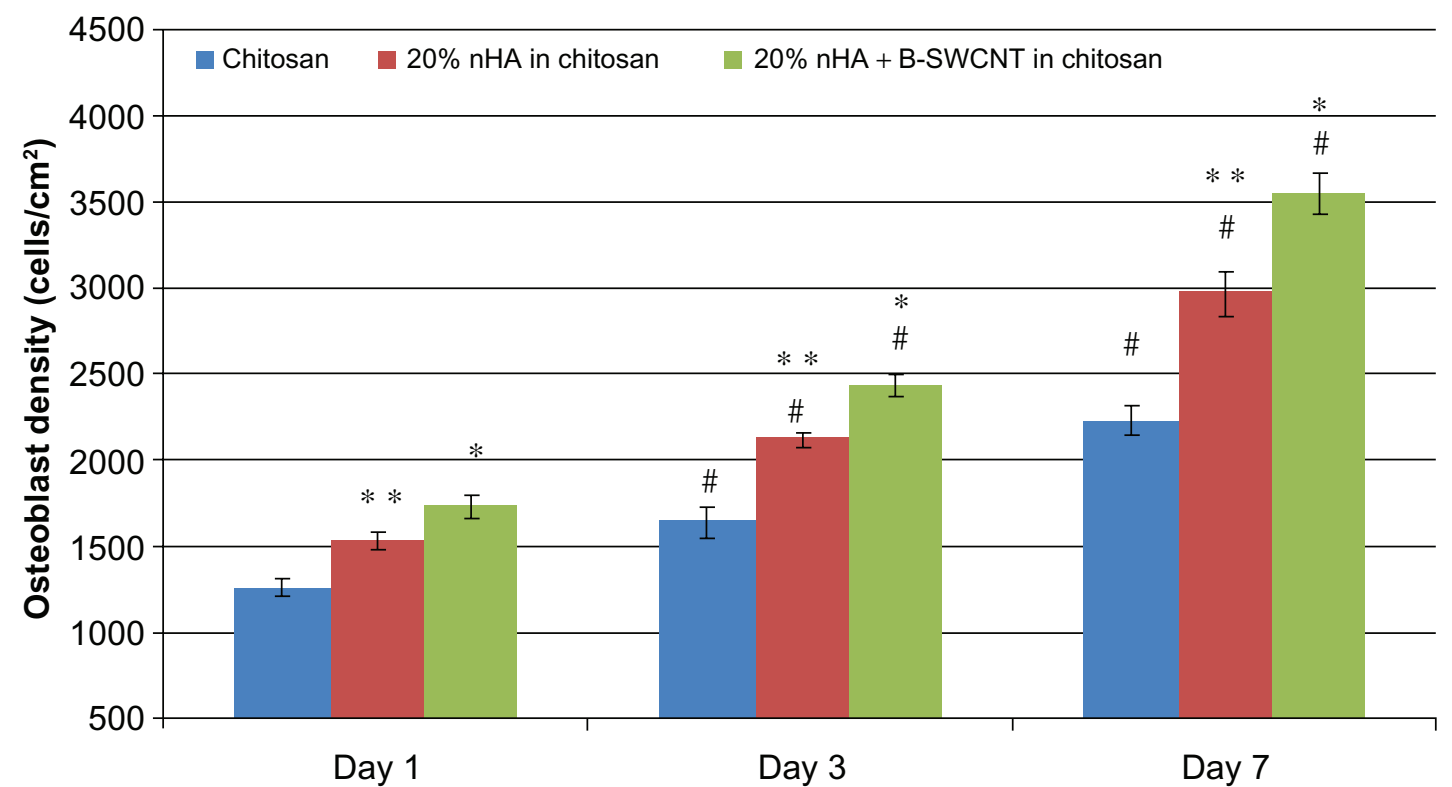

Figure I I Enhanced osteoblast proliferation on $\mathrm{nHA}$ and B-SWCNT chitosan nanocomposites.

Notes: Data are mean $\pm \mathrm{SEM} ; \mathrm{n}=9$. $* \mathrm{P}<0.05$ when compared to all other scaffolds at respective days; $* * P<0.05$ when compared to chitosan controls at respective days; and $\#$ P 0.05 when compared to respective scaffolds at I day.

on these scaffolds. Figure 10 shows live cells on $20 \%$ nanocrystalline hydroxyapatite + B-SWCNT chitosan when compared with a glass reference.

Furthermore, as shown in Figure 9, we can see that the method by which carbon nanotubes are synthesized (resulting in different SWCNT properties) can have a considerable effect on their ability to support bone cell growth. Although both B-SWCNT and N-SWCNT showed superior cytocompatibility properties in this study, B-SWCNT showed significantly more cell attachment than N-SWCNT in the chitosan/nanocrystalline hydroxyapatite scaffold. As discussed previously, in contrast with N-SWCNT, the synthesized B-SWCNT have longer lengths and an increased length/radius ratio when a magnetic field is applied to the arc discharge. These discrepancies in the geometric characteristics of the SWCNT may contribute to the differences in cell attachment seen in our study. In addition, it has been demonstrated that hydrogen bonds can be formed among SWNTs and chitosan, thus allowing them to form a strong matrix with stronger mechanical properties for loadbearing applications. ${ }^{9,38}$ Another advantage of B-SWCNT is their improved electrical conductivity. It is well known that electrical stimulation can promote osteogenesis at defective bone sites so B-SWCNT, with their improved electrical conductivity and excellent cytocompatibility properties, hold great potential for application in bone tissue engineering.

Figure 11 shows greatly enhanced bone cell proliferation in the $20 \%$ nanocrystalline hydroxyapatite in chitosan and
$20 \%$ nanocrystalline hydroxyapatite + B-SWCNT in chitosan scaffolds when compared with chitosan controls after 1,3 , and 7 days of culture. Specifically, the proliferation density of osteoblasts was the greatest on $20 \%$ nanocrystalline hydroxyapatite + B-SWCNT in chitosan scaffolds when compared with $20 \%$ nanocrystalline hydroxyapatite in chitosan and controls on respective days. In addition, the number of osteoblasts was also significantly greater on the $20 \%$ nanocrystalline hydroxyapatite in chitosan scaffolds than chitosan controls on respective days.

\section{Cell spreading differences on each scaffold}

Figure 12 shows confocal microscopy images of osteoblast spreading morphologies on $20 \%$ or $10 \%$ nanocrystalline hydroxyapatite in chitosan scaffolds, $20 \%$ nanocrystalline hydroxyapatite + B-SWCNT in chitosan scaffolds, and chitosan controls after one day of proliferation. These images provide evidence that nanocrystalline hydroxyapatite and SWCNT nanocomposite scaffolds can improve bone cell spreading when compared with chitosan controls without any nanomaterials. Specifically, Figure 12D shows long filopodia cell growth spreading onto the surfaces of the porous 20\% nanocrystalline hydroxyapatite + B-SWCNT chitosan scaffold, which is indicative of strong cell adhesion. In addition, Figure 12E and F shows three-dimensional morphology of attached cells in porous $10 \%$ nanocrystalline hydroxyapatite chitosan. A few round osteoblast cells are also visible in the image. 

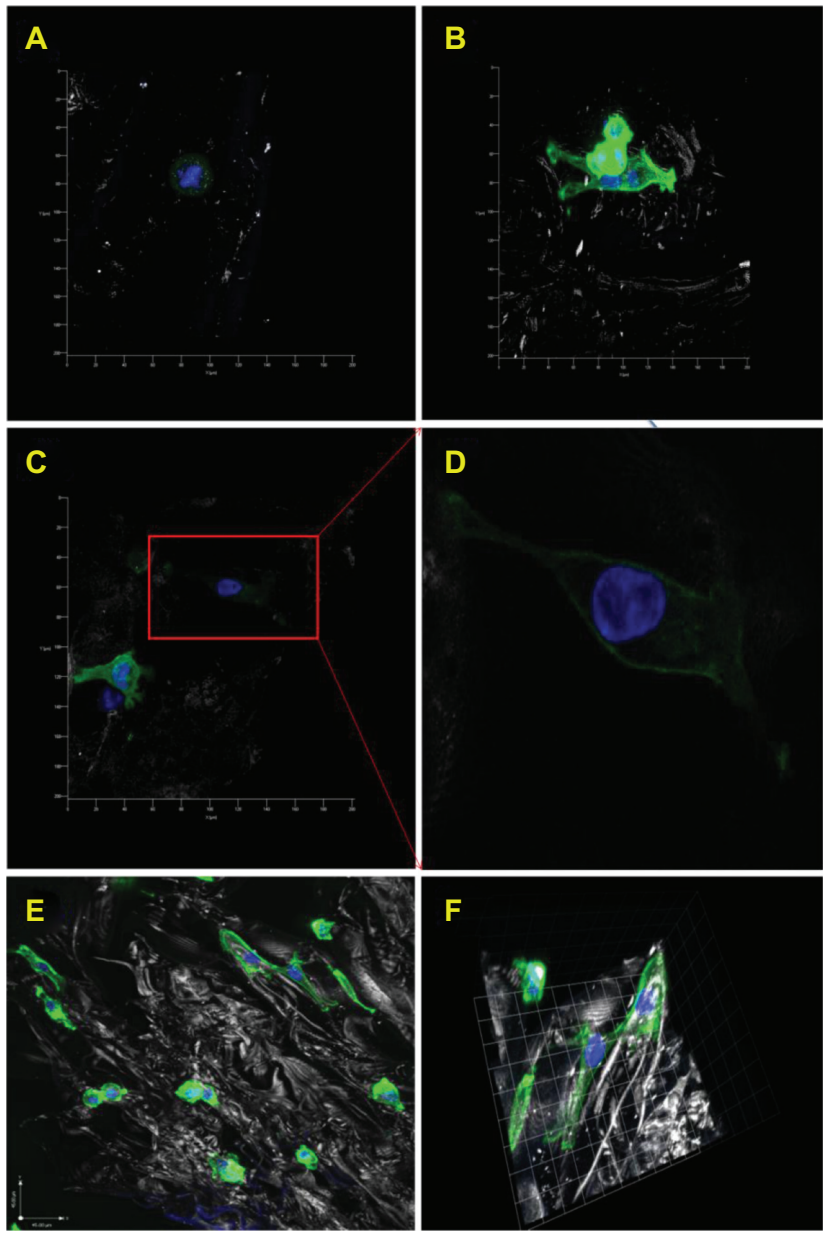

Figure 12 Confocal microscopy images of human osteoblasts on various chitosan scaffolds after one day proliferation. Typical cell morphologies on (A) chitosan controls; (B) $20 \% \mathrm{nHA}$ in chitosan scaffolds; (C) $20 \% \mathrm{nHA}+\mathrm{B}-\mathrm{SWCNT}$ in chitosan scaffolds and (D) enlarged cell morphology in image (C) which shows extended cell spreading on the novel biomimetic bone scaffold. In addition, (E) shows lower magnification confocal microscopy images of osteoblasts attached on I0\% nHA chitosan scaffold and (F) shows 3-D morphology of attached cells.

Note: Blue represents nuclei stained by DAPI; green represents cytoskeleton stained by rhodamine-phalloidin.

\section{Conclusion}

A series of novel porous nanocomposite scaffolds using magnetically synthesized B-SWCNT and hydrothermally treated nanocrystalline hydroxyapatite in a chitosan hydrogel were fabricated using a lyophilization procedure in this study. $20 \mathrm{wt} \%$ nanocrystalline hydroxyapatite + B-SWCNT in chitosan can significantly enhance the mechanical properties of the scaffold and synergistically improve scaffold cytocompatibility for osteoblast adhesion and proliferation. Interestingly, the study showed that osteoblasts favored B-SWCNT over N-SWCNT, demonstrating that cells may favor specific dimensions of nanotubes. In summary, this study demonstrated that our synthesized nanocrystalline hydroxyapatite and B-SWCNT with nanoscale biomimetic features created a favorable cellular environment to improve osteoblast functions, thus making them intriguing materials for further study in orthopedic applications.

\section{Acknowledgments}

This work was supported by the Institute for Biomedical Engineering at the George Washington University, GW University Facilitating Fund, and Pilot Project Award from the Clinical and Translational Science Institute at Children's National, and Award Number UL1RR031988 from the National Institutes of Health National Center for Research Resources. This work was also supported in part by the NSF/DOE Partnership in Plasma Science and Technology (NSF grant CBET-0853777, DOE grant DE-SC0001169.

\section{Disclosure}

The authors report no conflicts of interest in this work.

\section{References}

1. Myeroff C, Archdeacon M. Autogenous bone graft: donor sites and techniques. J Bone Joint Surg Am. 2011;93(23):2227-2236. 
2. Tibbitt MW, Anseth KS. Hydrogels as extracellular matrix mimics for 3D cell culture. Biotechnol Bioeng. 2009;103(4):655-663.

3. Zhang L, Webster TJ. Nanotechnology and nanomaterials: promises for improved tissue regeneration. Nanotoday. 2009;4(1):66-80.

4. Langer R, Vacanti JP. Tissue engineering. Science. 1993;260(5110): 920-926.

5. Zhang L, Hu J, Athanasiou KA. The role of tissue engineering in articular cartilage repair and regeneration. Crit Rev Biomed Eng. 2009; 37(1-2):1-57.

6. Mistry AS, Mikos AG. Tissue engineering strategies for bone regeneration. Adv Biochem Eng Biotechnol. 2005;94:1-22.

7. Rho JY, Kuhn-Spearing L, Zioupos P. Mechanical properties and the hierarchical structure of bone. Med Eng Phys. 1998;20(2):92-102.

8. Nguyen KT, West JL. Photopolymerizable hydrogels for tissue engineering applications. Biomaterials. 2002;23(22):4307-4314.

9. Venkatesan J, Kim SK. Chitosan composites for bone tissue engineeringan overview. Mar Drugs. 2010;8(8):2252-2266.

10. Ueno H, Mori T, Fujinaga T. Topical formulations and wound healing applications of chitosan. Adv Drug Deliv Rev. 2001;52(2):105-115.

11. Costa-Pinto AR, Reis RL, Neves NM. Scaffolds based bone tissue engineering: the role of chitosan. Tissue Eng Part B Rev. 2011;17(5): 331-347.

12. Di Martino A, Sittinger M, Risbud MV. Chitosan: a versatile biopolymer for orthopaedic tissue-engineering. Biomaterials. 2005;26(30): 5983-5990.

13. Gkioni K, Leeuwenburgh SC, Douglas TE, Mikos AG, Jansen JA. Mineralization of hydrogels for bone regeneration. Tissue Eng Part $B$ Rev. 2010;16(6):577-585.

14. Webster TJ, Ergun C, Doremus RH, Siegel RW, Bizios R. Specific proteins mediate enhanced osteoblast adhesion on nanophase ceramics. $J$ Biomed Mater Res. 2000;51(3):475-483.

15. Wei G, Ma PX. Structure and properties of nano-hydroxyapatite/ polymer composite scaffolds for bone tissue engineering. Biomaterials. 2004;25(19):4749-4757.

16. Sato M, Sambito MA,AslaniA, Kalkhoran NM, SlamovichEB, WebsterTJ Increased osteoblast functions on undoped and yttrium-doped nanocrystalline hydroxyapatite coatings on titanium. Biomaterials. 2006;27(11):2358-2369.

17. Zhang L, Ercan B, Webster TJ. Carbon nanotubes and nanofibers for tissue engineering applications. In: Liu C, editor. Carbon. Kerala, India Research Signpost; 2009.

18. Zhao Q, Yin J, Feng X, Shi Z, Ge Z, Jin Z. A biocompatible chitosan composite containing phosphotungstic acid modified single-walled carbon nanotubes. J Nanosci Nanotechnol. 2010;10(11):7126-7129.

19. Singh MK, Gracio J, LeDuc P, et al. Integrated biomimetic carbon nanotube composites for in vivo systems. Nanoscale. 2010;2(12): 2855-2863.

20. Armentano I, Marinucci L, Dottori M, et al. Novel poly(L-lactide) PLLA/SWNTs nanocomposites for biomedical applications: material characterization and biocompatibility evaluation. J Biomater Sci Polym Ed. 2011;22(4-6):541-556.

21. Sahithi K, Swetha M, Ramasamy K, Srinivasan N, Selvamurugan N Polymeric composites containing carbon nanotubes for bone tissue engineering. Int J Biol Macromol. 2010;46(3):281-283.

22. Sitharaman B, Shi X, Walboomers XF, et al. In vivo biocompatibility of ultra-short single-walled carbon nanotube/biodegradable polymer nanocomposites for bone tissue engineering. Bone. 2008;43(2):362-370.
23. Shi X, Hudson JL, Spicer PP, Tour JM, Krishnamoorti R, Mikos AG Injectable nanocomposites of single-walled carbon nanotubes and biodegradable polymers for bone tissue engineering. Biomacromolecules. 2006;7(7):2237-2242.

24. Harrison BS, Atala A. Carbon nanotube applications for tissue engineering. Biomaterials. 2007;28(2):344-353.

25. Zhang L, Chen Y, Rodriguez J, Fenniri H, Webster TJ. Biomimetic helical rosette nanotubes and nanocrystalline hydroxyapatite coatings on titanium for improving orthopedic implants. Int J Nanomedicine. 2008;3(3):323-333.

26. Manjubala I, Ponomarev I, Wilke I, Jandt KD. Growth of osteoblast-like cells on biomimetic apatite-coated chitosan scaffolds. J Biomed Mater Res B Appl Biomater. 2008;84(1):7-16.

27. Reves BT, Bumgardner JD, Cole JA, Yang Y, Haggard WO Lyophilization to improve drug delivery for chitosan-calcium phosphate bone scaffold construct: a preliminary investigation. $J$ Biomed Mater Res B Appl Biomater. 2009;90(1):1-10.

28. Zhang L, Rakotondradany F, Myles AJ, Fenniri H, Webster TJ. Arginineglycine-aspartic acid modified rosette nanotube-hydrogel composites for bone tissue engineering. Biomaterials. 2009;30(7):1309-1320.

29. Liu X, Lim JY, Donahue HJ, Dhurjati R, Mastro AM, Vogler EA. Influence of substratum surface chemistry/energy and topography on the human fetal osteoblastic cell line hFOB 1.19: Phenotypic and genotypic responses observed in vitro. Biomaterials. 2007;28(31):4535-4550.

30. Li J, Shashurin A, Kundrapu M, Keidar M. Simultaneous synthesis of single-walled carbon nanotubes and graphene in a magneticallyenhanced arc plasma. J Vis Exp. 2012;60:3455

31. Volotskova O, Fagan J, Phelan FR, Kumar S, Shashurin A, Keidar M Tailored distribution of single-wall carbon nanotubes from arc plasma synthesis using magnetic fields. ACS Nano. 2010;4(9):5187-5192.

32. Keidar M, Levchenko I, Arbel T, Alexander M, Waas AM, Ostrikov K. Magnetic-field-enhanced synthesis of single wall carbon nanotubes in arc discharge. J Appl Phys. 2008;103:094318.

33. Zhang L, Rodriguez J, Raez J, Myles AJ, Fenniri H, Webster TJ. Biologically inspired rosette nanotubes and nanocrystalline hydroxyapatite hydrogel nanocomposites as improved bone substitutes. Nanotechnology. 2009;20(17):175101.

34. Khang D, Kim SY, Liu-Snyder P, Palmore GT, Durbin SM, Webster TJ Enhanced fibronectin adsorption on carbon nanotube/poly(carbonate) urethane: independent role of surface nano-roughness and associated surface energy. Biomaterials. 2007;28(32):4756-4768.

35. Webster TJ. Nanophase ceramics: the future orthopedic and dental implant material. In: Ying JY, editor. Advances in Chemical Engineering. New York, NY: Academic Press; 2001.

36. Kaplan F, Hayes WC, Keaveny TM, Boskey A, Einhorn TA, Lannotti J. Form and function of bone. In: Simon SR, editor. Orthopedic Basic Science. Rosemont, IL: American Academy of Orthopedic Surgeons; 1994.

37. Webster TJ, Schadler LS, Siegel RW, Bizios R. Mechanisms of enhanced osteoblast adhesion on nanophase alumina involve vitronectin. Tissue Eng. 2001;7(3):291-301.

38. Wang SF, Shen L, Zhang WD, Tong YJ. Preparation and mechanical properties of chitosan/carbon nanotubes composites. Biomacromolecules. 2005;6(6):3067-3072.
International Journal of Nanomedicine

\section{Publish your work in this journal}

The International Journal of Nanomedicine is an international, peerreviewed journal focusing on the application of nanotechnology in diagnostics, therapeutics, and drug delivery systems throughou the biomedical field. This journal is indexed on PubMed Central, MedLine, CAS, SciSearch ${ }^{\circledR}$, Current Contents ${ }^{\circledR} /$ Clinical Medicine,

\section{Dovepress}

Journal Citation Reports/Science Edition, EMBase, Scopus and the Elsevier Bibliographic databases. The manuscript management system is completely online and includes a very quick and fair peer-review system, which is all easy to use. Visit http://www.dovepress.com/ testimonials.php to read real quotes from published authors. 